FciDioc

\section{Diabetic Foot Infection and Worsening Kidney Function: Implication for Health Care in the Developing World}

Anitha Rani A ${ }^{1}$, Viswanathan $\mathrm{V}^{2 *}$

${ }^{1}$ Post Doctoral Research Fellow, Prof. M. Viswanathan Diabetes Research Centre, Royapuram, Chennai, Tamil Nadu, India.

${ }^{2}$ Head \& Chief Diabetologist, M.V. Hospital for Diabetes and President, Prof. M.Viswanathan Diabetes Research Centre, West Madha Church Street, Royapuram, Chennai, Tamil Nadu, India.

\title{
Abstract
}

Background: Diabetic foot infection (DFI) and Chronic Kidney Disease (CKD) are two health care issues causing considerable burden in the developing world. The current study was aimed to examine the effect of DFI in declining renal function among patients with Type 2 Diabetes Mellitus (T2DM).

Methods: A total of 412 patients have been included in a prospective 12 months follow-up study. The study patients were categorized into Group I: T2DM with CKD and DFI, Group II: T2DM with CKD, Group III: T2DM with DFI and without CKD and Group IV- T2DM without any complications. Demographic, anthropometric and clinical parameters were recorded accordingly.

Results: Significant fall in eGFR was observed within group I at $6^{\text {th }}$ month $(p<0.0001)$ and $12^{\text {th }}$ month $(p<0.0001)$. In group II fall in eGFR was noticed in $3^{\text {rd }}$ month $(\mathrm{p}<0.004) ; 6^{\text {th }}$ month and $(\mathrm{p}<0.004) ; 12^{\text {th }}$ months $(\mathrm{p}<0.0001)$ and in group III significant fall in eGFR was observed in $3^{\text {td }}$ month $(p<0.0001), 6^{\text {th }}$ month $(p<0.004)$ and 12 months $(p<0.004)$. No significant fall in eGFR was observed in group IV. The mean differences of eGFR from 0 to 12 months were $11.01,8.36,3.52$, and 1.2 in all the groups respectively.

Conclusions: There was a significant reduction in eGFR among CKD patients with DFI and DFI patients without CKD. Therefore development of DFI may cause decline in renal function irrespective of CKD status and preventive steps to prevent a DFI is mandatory in all T2DM.

Keywords: Diabetic Foot Infection; Chronic Kidney Disease; eGFR; T2DM.

\section{Introduction}

Diabetes mellitus (DM) remains one of the most serious worldwide health challenges. Diabetic foot infection (DFI) and diabetic nephropathy are the major complications of DM, which increases morbidity and mortality of patients. Among various other complications associated with Type 2 Diabetes Mellitus (T2DM), DFI and its recurrence represents a significant and often challenging clinical problem, which is mainly due to either diabetic neuropathy and/or peripheral arterial disease (PAD) [1-4]. DFI affects nearly 12 to $25 \%$ of patients with T2DM throughout their lives and it is the leading cause for hospital admission among diabetic patients in India. This is mainly due to socio-cultural factors \& lack of knowledge on diabetic foot complications [5]. The etiology of DFI is multifactorial and the management of
DFI and its consequences increases the burden on both health and social services. In developing countries, the common causes of death after amputation in T2DM patient are infection and cardiovascular events. Further myocardial infarction was the most common among post amputated T2DM patient in India [6].

Diabetic foot ulcers and renal function in DM show a strong correlation between the classifications of diabetic foot ulcer and eGFR [7]. Indians are at heightened risk for nephropathy, more than any other ethnic groups and declining of GFR was also faster. T2DM patients in India are at high risk of developing Chronic Kidney disease (CKD) and diabetes is now the leading cause of end stage renal disease (ESRD) in many regions of India [8]. The burden of CKD among the DM remains to be a global threat, as the treatment is expensive and lifelong. In developing

\footnotetext{
*Corresponding Author:

Vijay Viswanathan,

Head \& Chief Diabetologist, M.V. Hospital for Diabetes and President, Prof. M.Viswanathan Diabetes Research Centre, No: 4, West Madha Church Street, Royapuram, Chennai, 600013, Tamil Nadu, India.

E-mail: drvijay@mvdiabetes.com/researchcommunication@mvdiabetes.com
}

Received: October 17, 2017

Accepted: November 14, 2017

Published: November 21, 2017

Citation: Anitha Rani A, Viswanathan V. Diabetic Foot Infection and Worsening Kidney Function: Implication for Health Care in the Developing World. Int J Diabetol Vasc Dis Res, 2017;5(5):208-213. doi: http://dx.doi.org/10.19070/2328-353X-1700042

Copyright: Viswanathan $\mathbf{V}^{\odot} 2017$. This is an open-access article distributed under the terms of the Creative Commons Attribution License, which permits unrestricted use, distribution and reproduction in any medium, provided the original author and source are credited. 
countries like India, the direct cost involved in hospital admission for treating diabetic patients with CKD was considerably higher when compared to that of diabetic patients without CKD [9]. In a large cohort of 90,617 diabetic subjects with, a strong association between the degree/severity of renal impairment and the onset of both diabetic foot ulcer and lower extremity amputation was demonstrated [10]. T2DM patients with ESRD on dialysis with foot ulcer, shows significant association with PVD [11]. Most of these studies emphasized the association between CKD and peripheral arterial disease rather than with DFI $[12,13]$. CKD is an independent risk factor for the development of foot lesions in the diabetic population [14]. Though there is a close association between CKD and DFI it does not prove a causal relationship between the two conditions [15] and several possible common underlying pathophysiological mechanisms may underpin it.

Although every practicing clinician may have the impression that $\mathrm{DFI}$ is more common in patients with CKD, there are surprisingly very little data on the relationship between DFI and CKD in patients with diabetes and majority of studies have investigated only among dialysis patients $[10,16,17]$. There is a paucity of data which focused on the overall occurrence of DFI among those with CKD and diabetes. Hence the main objective of this study was to investigate the effect of Diabetic foot infection (DFI) on the renal function among patients with and without CKD at the time of onset of DFI.

\section{Research Design and Methods}

Prospective follow up study was conducted among the patients with T2DM, who attended the outpatient Diabetes clinic during the study period of October 2014 to March 2017 in a tertiary care hospital in India. Study population includes age matched patients with T2DM with pre-existing diabetic kidney disease (stage 2 and 3 CKD and with a DFI (grade 2 and 3: University of Texas foot ulcers grading), patients with T2DM with pre-existing kidney disease (stage 2 and 3 CKD) without DFI, Diabetic patients with foot ulcers and T2DM subjects without any complications. Patients aged $\geq 25$ years with duration of diabetes more than three years were included in the study.

Patients with severe and or progressive foot infection, any acute concurrent illness in the previous 6 months (e.g. malignancy, severe gastrointestinal disease), history of non-diabetic or obstructive kidney disease, history of a cardiovascular or cerebrovascular accident, diabetic foot ulcers which had not healed within six months, patients with type 1 diabetes and gestational diabetes and those with incomplete laboratory data were excluded from the study.

\section{Assessment of Foot/Ulcers}

Diabetic Foot Ulcer was categorized based on the classification of the University Of Texas Health Science Center San Antonio (UT). Neuropathy was identified using the Biothesiometer (from diabetic foot care India Pvt. Ltd.) to determine the vibration perception threshold (a value of $\geq 25$ volts was considered as abnormal) and peripheral arterial disease was determined using peripheral vascular Doppler (Versalab).

\section{Assessment of Renal Function}

Study subjects were grouped into the CKD stages according to the eGFR (CKD EPI formula) and presence of albuminuria for three consecutive visits. The eGFR was calculated based on CKD - EPI equation which expressed as a single equation as [18]:

$\mathrm{eGFR}=141 \times \min ((\mathrm{Scr} / x,) 1)^{\alpha} \times \max ((\mathrm{Scr} / x), 1)^{-1.209} \times 0.993^{\mathrm{Age}} \times$ 1.018 [if female] $\times 1.159$ [if black]

Stratification of CKD was based on the eGFR stages as per KDOQI guidelines [19]. Pre-existing diabetic kidney disease (DKD) was defined as a history of an elevated urinary albumin excretion rate (UAER - immunoturbidimetric method) using an overnight timed urine collection (range: $<20 \mu \mathrm{g} / \mathrm{min}$ - Normal; $>20 \mu \mathrm{g} / \mathrm{min}$-Abnormal), associated with reduced eGFR. Creatinine was estimated by Jaffe's kinetic method (this enzymatic kinetic test was carried out without deproteinization, [20]), urinary albumin was estimated by immuno-turbidimetric procedure and Urinary protein was determined using pyrogallol method (biochemical method). Estimated glomerular filtration rate and albumin creatinine ratio were used for assessing renal function. Estimated glomerular filtration rate was calculated based on CKD - EPI equation. This equation was developed in 2009 [18] and intended to be more generalizable across various clinical settings.

\section{Clinical and Biochemical Investigations}

Demographic and anthropometric details like age, height, weight, blood pressure, duration of diabetes, medical history, family history of diabetes, history of kidney disease, foot ulcer, history of micro and macro vascular complications, history of hypertension, history of smoking and alcohol were obtained from patients proforma and medical records of the study subjects. Basic blood parameters like Fasting blood glucose (GOD - POD method), postprandial blood glucose (GOD - POD method), HbA1c (HPLC method using variant turbo equipment [Bio-Rad]), renal function test and lipid profile (Total Cholesterol - CHOD - PAP method, Triglyceride - GPO method, HDL and LDL Direct IMM) were measured for all the study subjects. All other biochemical parameters were estimated using BS400 biochemistry auto analyzer. Diagnosis of T2DM subjects was selected based on previous history of diabetes and the criteria of the World Health Organization. The study was approved by the Institutional Research committee.

\section{Statistical Analysis}

Data were presented in mean $( \pm)$ Standard deviation. Student's $t$ test was used to compare continuous variable, Chi-square test was used to compare the proportions between the study groups. ANOVA was used for comparison of quantitative variables. Difference in time period was analyzed using ANOVA for repeated measures with the four groups $(\mathrm{CKD}+\mathrm{DFI}, \mathrm{CKD}, \mathrm{DFI}$ and $\mathrm{T} 2 \mathrm{DM})$ as between subject factor and different months as within subject factor. Multiple comparisons were performed using bonferroni correction for all the study groups Mauchly's test indicated that the assumption of sphericity has been violated, therefore degrees of freedom were corrected using GreenhouseGeisser estimates of sphericity $(\epsilon=0.892)$. A p value of $<0.05$ 
was considered statistically significant. All statistical analyses were performed using Statistical Package for the Social Sciences (SPSS) Version 20, (Illinois, USA) software.

\section{Results}

A total of 412 T2DM patients (Male: Female/250:162) were recruited based on the inclusion and exclusion criteria for a prospective study with a 12 month follow-up period $\left(0,3^{\text {rd }}\right.$, $6^{\text {th }}$ and $12^{\text {th }}$ month). Based on CKD and DFI, study subjects were categorized into four groups. Group I includes diabetic subjects with chronic kidney disease and diabetic foot infection $(\mathrm{CKD}+\mathrm{DFI}, \mathrm{n}=93)$, group II includes diabetic subjects with chronic kidney disease without DFI (CKD, $n=97)$, group III includes diabetic subjects with foot infection and without CKD (DFI, $n=108$ ) and group IV included type 2 diabetic subjects without any complications (T2DM, n=114).

Table 1 shows the demographic, anthropometric and clinical details of all the study groups. Statistical significance were observed in age $(\mathrm{P}<0.001)$, gender $(\mathrm{P}<0.005)$ duration of diabetes $(\mathrm{P}<0.001)$ and duration of hypertension $(<0.001)$. Neuropathy was higher in group I (34.5\%) followed by group III (33\%) and group II (12 $\%)$ respectively. Presence of retinopathy was higher in group II (32\%), followed by group I (19\%) and group III (7.7\%). Among the study groups presence of both neuropathy and retinopathy was higher in group III (11.9\%).

The effect of time on eGFR of different groups (within subject effect), shows significant difference, which is reflected by repeated measure ANOVA, using Mauchly's test of Sphericity, $(\mathrm{P}<0.0001)$, the Greenhouse-Geisser correction was also statistically significant, $(\mathrm{F}=9.016 ; \mathrm{P}<0.0001)$ (Figure 1). The mean differences of eGFR from 0 to 12 months were $11.01,8.36,3.52$, and 1.2 in all the groups respectively (Figure 2). Table 2 represents the eGFR of all the study groups. Significant fall in eGFR was observed within group I at $6^{\text {th }}$ month $(p<0.0001)$ and $12^{\text {th }}$ month $(p<0.0001)$. In group II fall in eGFR was noticed in $3^{\text {rd }}$ month $(p<0.004) ; 6^{\text {th }}$ month and $(p<0.004) ; 12^{\text {th }}$ months $(p<0.0001)$ and in group III significant fall in eGFR was observed in 3rd month $(p<0.0001)$, $6^{\text {th }}$ month $(p<0.004)$ and 12 months $(p<0.004)$. No significant fall in eGFR was observed in group IV. Time and group interaction is significant which indicates the effect of eGFR over the time is different for different group. The mean trend is significantly different in eGFR over the period of time in all the groups (Table $3)$.

Table 4 shows the comparison of reduction in eGFR among different groups from baseline to follow up. When comparing the $0 \mathrm{Vs} 6^{\text {th }}$ month eGFR, reduction was significantly higher in Group I (CKD and DFI: $6.85 \mathrm{ml}$ ), followed by group III (DFI: 4.10) and group II (CKD: 4.25). When comparing the $6^{\text {th }} \mathrm{Vs} 12^{\text {th }}$ month eGFR, in the CKD group there was a significant reduction in

Table 1. Demographic and anthropometric characteristic of the study groups.

\begin{tabular}{|c|c|c|c|c|c|}
\hline Characteristic & Group I & Group II & Group III & Group IV & P- Value \\
\hline Ages (yrs) & $58.6 \pm 8.96$ & $59.2 \pm 8.09$ & $59.8 \pm 8.33$ & $58.7 \pm 10.75$ & 0.76 \\
\hline Gender (M:F) & $65: 28$ & $68: 29$ & $56: 52$ & $61: 53$ & 0.005 \\
\hline Duration of Diabetes (yrs) & $11.4 \pm 6.40$ & $13.5 \pm 7.17$ & $11.6 \pm 6.22$ & $9.4 \pm 5.29$ & $<0.001$ \\
\hline Duration of Hypertension (yrs) & $5.45 \pm 2.75$ & $4 \pm 2.4$ & $4.38 \pm 2.71$ & $1.54 \pm 1.56$ & $<0.001$ \\
\hline Family history of Diabetes (\%) & 51.60 & 60.80 & 61.10 & 72.80 & 0.018 \\
\hline Smoking (\%) & 4.25 & 7.20 & 3.70 & 7.90 & 0.138 \\
\hline Alcohol (\%) & 2.20 & 6.20 & 8.30 & 4.40 & 0.326 \\
\hline Neuropathy (\%) & 34.5 & 12 & 33 & - & \\
\hline Retinopathy (\%) & 19 & 32 & 7.7 & - & \\
\hline Neuropathy \& Retinopathy (\%) & 15 & 12 & 11.9 & - & \\
\hline
\end{tabular}

Figure 1. Trend analysis for the study groups over the time period.

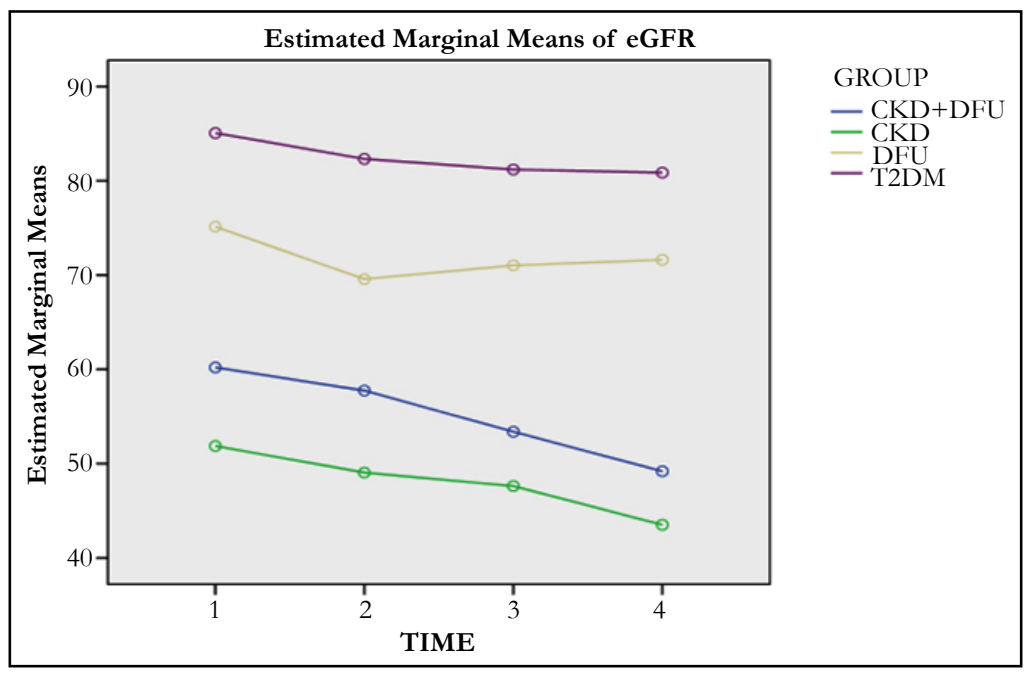


Figure 2. Comparison of eGFR from baseline to 12 month follow-up among the study groups.

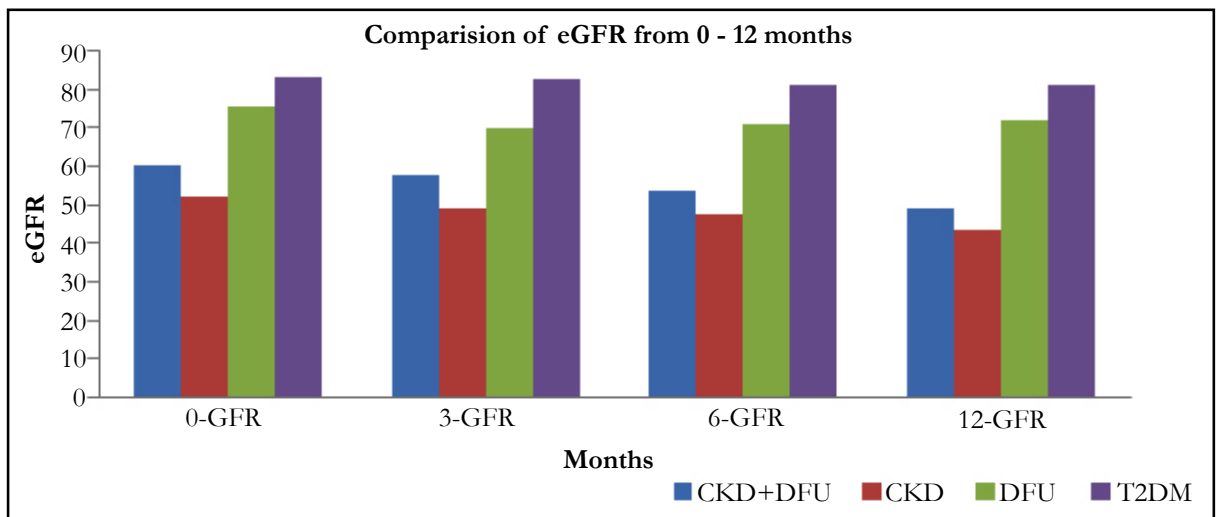

Table 2. Comparison of eGFR from baseline to follow up in all the groups.

\begin{tabular}{|c|c|c|c|c|}
\hline Group & 0 Month GFR & $\mathbf{3}^{\text {rd }}$ Month GFR & $\mathbf{6}^{\text {th }}$ Month GFR & 12 $^{\text {th }}$ Month GFR \\
\hline G1 CKD and DFI & $60.2 \pm 18.95$ & $57.75 \pm 18.51$ & $53.39 \pm 14.97^{*}$ & $49.19 \pm 13.92^{*}$ \\
\hline G2 CKD & $51.88 \pm 17.48$ & $49.05 \pm 16.66^{* *}$ & $47.63 \pm 16.18^{* *}$ & $43.52 \pm 14.53^{*}$ \\
\hline G3 DFI & $75.13 \pm 16.07$ & $69.57 \pm 17.14^{*}$ & $71.03 \pm 14.87^{* *}$ & $71.61 \pm 13.7^{* *}$ \\
\hline G4 T2DM & $82.06 \pm 9.64$ & $82.32 \pm 14.04$ & $81.19 \pm 14.87$ & $80.86 \pm 13.55$ \\
\hline
\end{tabular}

$\mathrm{P}$ value $<0.0001^{*}, \mathrm{P}<0.004^{* *}$ is considered statistically significant.

Table 3. Trend Analysis for all the Groups over the Time Period.

\begin{tabular}{|c|c|c|c|c|c|c|}
\hline Source & Time & Type III Sum of Squares & df & Mean Square & F & Sig. \\
\hline \multirow{4}{*}{ Time vs Group } & Linear & 2459.759 & 3 & 819.92 & 13.228 & $<0.0001$ \\
\cline { 2 - 7 } & Quadratic & 1036.605 & 3 & 345.535 & 7.586 & $<0.0001$ \\
\cline { 2 - 7 } & Cubic & 280.335 & 3 & 93.445 & 2.911 & 0.034 \\
\hline
\end{tabular}

Table 4. Comparison of eGFR from baseline to follow up within the group.

\begin{tabular}{|c|c|c|}
\hline \multirow[t]{2}{*}{ Group } & \multicolumn{2}{|c|}{ eGFR Reduction (ml/ min/1.73sqm body surface area) } \\
\hline & 0 month Vs $6^{\text {th }}$ month eGFR & 6th month Vs $12^{\text {th }}$ month eGFR \\
\hline G1 CKD + DFI & $6.85(<0.0001)^{*}$ & $4.20(<0.0001) *$ \\
\hline G2 CKD & $4.25(0.002)^{*}$ & $4.11(<0.0001)^{*}$ \\
\hline G3 DFI & $4.10(0.001)^{*}$ & $0.58(0.004)^{* *}$ \\
\hline G4 T2DM & $0.87(0.689)$ & $0.33(0.79)$ \\
\hline
\end{tabular}

$\mathrm{P}$ value $<0.0001 *, \mathrm{P}<0.004 * *$ is considered statistically significant.

eGFR and similar fall in eGFR was observed in CKD with DFI group. Whereas in the DFI group, the reduction of eGFR was similar to the reduction observed in group 4 (T2DM). The wound healing time in DFI group was 40.8 days (1.5 months), where as in CKD with DFI group the healing time was 60.5 days which is 2 months.

\section{Discussion}

To our knowledge this is the first study of this kind to study the role of DFI on the renal function at the time of onset of DFI. Diabetic foot ulcers occurs significantly more often in patients with nephropathy, macroalbuminuria, end-stage renal disease, but not in those with microalbuminuria [21]. Diabetic foot infection appears to contribute towards an Acute Kidney Injury (AKI) like situation in people with Diabetes. Although there are many potential mechanisms used to explain the onset of CKD \& DFI in diabetes, it is fascinating to note that structurally in many ways the onset of CKD is similar to the onset of DFI [6]. At the same time, there are no plausible mechanisms through which DFI could have a direct/causal impact among patients with CKD. These two complications perhaps share common/similar pathophysiological mechanisms such as increased inflammation, endothelial dysfunction and oxidative stress. Further they shares common risk factors such as obesity, hypertension, duration of diabetes and older age [22-24]. Causal pathways to foot ulceration are multifactorial and involve combinations of physiological and mechanical factors, self-care, and treatment factors. Diabetic 
nephropathy has been identified to be an important risk factor for DFI and amputation $[25,26]$. Present highlighted that in patients with DFI there is a reduction in eGFR and when the infection subsides the eGFR improved, whereas in patients with pre-existing CKD the decrease in eGFR was observed in all the follow-up periods. Among patients with both CKD and DFI, fall in eGFR was similar to that of DFI patients, however the eGFR continues to fall and fails to improve after the DFI subsides. Thus DFI seems to worsen the CKD stage, as the fall in eGFR was higher in CKD with DFI group. A significant finding in this study is the fact that there is a reduction of eGFR among patients DFI with normal eGFR before DFI. Further this study also found that the healing time was also high in patients with CKD and DFI group, when compared with that of DFI group. AKI and CKD share common risk factors and disease modifiers. When AKI occurs without preexisting kidney disease, CKD may still develop. Conversely, the presence of CKD is an important risk factor for the development of AKI.

The underlying mechanism in the progression of renal dysfunction is incompletely understood, animal model studies showed several casual pathways which includes either disordered regeneration or maladaptive repair or both may initiate the ongoing organ dysfunction [27]. Reduced GFR higher than normal range in people with diabetes tend to aggravate DFI and ultimately leads to amputation [28]. Renal disease after AKI episodes can be determine by the reduction in eGFR, temporal balance of effective and maladaptive repair reversibility of the injury and regenerative mechanism [29].

In the present study, conducted among patients with minimal to moderate CKD (stage $2 \& 3$ ); DFI appears to worsen the eGFR decline. DFI healing is worst in patients with higher creatinine levels. Patients with declining eGFR are prone to DFI. In a developing country, the burden of CKD is higher [8] and it is further escalated due to DFI. If DFI occurs in patients with CKD stage 3 and stage 4, it may worsen the GFR decline and lead to ESRD. In order to avoid this situation prevention plays a major role. Foot infection in developing countries is a neglected condition [30]. The consequences of persistent and poorly controlled hyperglycemia lead to neuropathic and vascular abnormalities that cause foot deformities, ulceration and incidence of foot infection. There is a need to increase the awareness on diabetes and its complications by advocating a healthy life style and emphasizing the importance of simple measures like maintaining the blood pressure and blood sugar under control, reducing salt intake, reducing smoking and alcohol habits and following good practices like proper foot care.

\section{Conclusion}

The present study concluded that there is greater decline in eGFR among CKD patients who developed foot infection and also among DFI patients with no evidence of CKD at baseline. There is a strong association between the degree of renal function impairment and diabetic foot ulcers. The levels of eGFR drop significantly with the onset of diabetic foot infection among T2DM patients with kidney disease. Thus development of DFI per se may cause decline in renal function irrespective of CKD status. Every effort must be taken to prevent DFI in people with diabetes especially among those with a lower eGFR. Hence DFI has to be actively treated to prevent a decline in
eGFR. The health care system has to focus on the early healing of wound by imparting education and treatment modalities. A multidisciplinary approach is needed to reduce the development of DFI in people with diabetes. The health care system should involve a diabetologist and a podiatrist for the prevention and the management of Diabetic foot infection.

\section{Acknowledgement}

We thank Selvakumar, IT Department, and Mr. Sri Ram for statistical help and Ms. Bamila selvaraj for helping in patient identification.

\section{References}

[1]. Viswanathan V, Rao VN. Managing diabetic foot infection in India. Int J Low Extrem Wounds. 2013 Jun;12(2):158-166. PubMed PMID:23667101.

[2]. Vijay V, Narasimham DV, Seena R, Snehalatha C, Ramachandran A. Clinical profile of diabetic foot infections in south India - a retrospective study. Diabet Med. 2000 Mar;17(3):215-218. PubMed PMID:10784226.

[3]. Aziz KM. The Diabetic Foot Syndrome an Ignored and Potential Problem in Medical Practice. Int J Diabetol Vasc Dis Res. 2013 Sep 11;1(1):1-3.

[4]. Aziz KM. Association between high risk foot, retinopathy and HbA1C in Saudi diabetic population. Pak J Physiol. 2010;6(2):22-28.

[5]. Vijay V, Snehalatha C, Ramachandran A. Socio-cultural practices that may affect the development of the diabetic foot. IDF Bulletin. 1997;42:10-13.

[6]. Viswanathan V, Wadud JR, Madhavan S, Rajasekar S, Kumpatla S, Lutale $\mathrm{JK}$, et al. Comparison of post amputation outcome in patients with type 2 diabetes from specialized foot care centres in three developing countries. Diabetes Res Clin Pract. 2010 May;88(2):146-150. PubMed PMID: 20299119.

[7]. Margolis DJ, Hofstad O, Feldman HI. Association between renal failure and foot ulcer or lower-extremity amputation in patients with diabetes. Diabetes care. 2008 Jul;31(7):1331-1336. PubMed PMID:18390800.

[8]. Modi GK, Jha V. The incidence of end-stage renal disease in India: a population-based study. Kidney Int. 2006 Dec;70(12):21312133. PubMed PMID:17063176.

[9]. Satyavani K, Kothandan H, Jayaraman M, Viswanathan V. Direct costs associated with chronic kidney disease among type 2 diabetic patients in India. Indian J Nephrol. 2014 May;24(3):141-147. PubMed Central PMCID: PMC4127832.

[10]. Kumpatla S, Kothandan H, Tharkar S, Viswanathan V. The costs of treating long term diabetic complications in a developing country: a study from India. J Assoc Physicians India. 2013 Feb;61(2):102-109. PubMed PMID: 24471248.

[11]. O'Hare AM, Bacchetti P, Segal M, Hsu CY, Johansen KL. Factors associated with future amputation among patients undergoing hemodialysis: results from the Dialysis Morbidity and Mortality Study Waves 3 and 4. Am J Kidney Dis. 2003 Jan;41(1):162-70. PubMed PMID: 12500233.

[12]. O'Hare AM, Glidden DV, Fox CS, Hsu CY. High prevalence of peripheral arterial disease in persons with renal insufficiency. Circulation. 2004 Jan 27;109(3):320.

[13]. O'Hare AM, Vittinghoff E, Hsia J, Shlipak MG. Renal insufficiency and the risk of lower extremity peripheral arterial disease: results from the Heart and Estrogen/Progestin Replacement Study (HERS). J Am Soc Nephrol. 2004 Apr;15(4):1046-51. PubMed PMID: 15034108.

[14]. Lewis S, Raj D, Guzman NJ. Renal failure: implications of chronic kidney disease in the management of the diabetic foot. Semin Vasc Surg. 2012 Jun;25(2):82-88. PubMed PMID: 22817857.

[15]. Dinh TL, Veves A. A review of the mechanisms implicated in the pathogenesis of the diabetic foot. Int J Low Extrem Wounds. 2005 Sep;4(3):154-9. PubMed PMID: 16100096.

[16]. Sämann A, Tajiyeva O, Müller N, Tschauner T, Hoyer H, Wolf G, et al. Prevalence of the diabetic foot syndrome at the primary care level in Germany: a cross-sectional study. Diabet Med. 2008 May;25(5):557-63. PubMed PMID:18346154

[17]. Papanas N, Liakopoulos V, Maltezos E, Stefanidis I. The diabetic foot in end stage renal disease. Ren Fail. 2007;29(5):519-28. PubMed PMID:17654312.

[18]. Levey AS, Stevens LA, Schmid CH, Zhang YL, Castro AF, Feldman HI, et al. A new equation to estimate glomerular filtration rate. Ann Intern Med. 2009 May 5;150(9):604-12. PubMed PMID:19414839.

[19]. National Kidney Foundation. K/DOQI clinical practice guidelines for chronic kidney disease: evaluation, classification, and stratification. Am J Kidney Dis. 2002 Feb;39(2 Suppl 1):S1-266. PubMed PMID:11904577. 
[20]. Mazzachi BC, Peake MJ, Ehrhardt V. Reference range and method comparison studies for enzymatic and Jaffe creatinine assays in plasma and serum and early morning urine. Clin Lab. 2000;46(1-2):53-55. PubMed PMID: 10745982.

[21]. Lavery LA, Armstrong DG, Vela SA, Quebedeaux TL, Fleischli JG. Practical criteria for screening patients at high risk for diabetic foot ulceration. Arch Intern Med. 1998 Jan 26;158(2):157-162. PubMed PMID: 9448554.

[22]. Fernando DJ, Hutchison A, Veves A, Gokal R, Boulton AJ. Risk factors for non-ischaemic foot ulceration in diabetic nephropathy. Diabet Med. 1991 Apr;8(3):223-225. PubMed PMID:1828736.

[23]. Dronavalli S, Duka I, Bakris GL. The pathogenesis of diabetic nephropathy. Nat Clin Pract Endocrinol Metab. 2008 Aug;4(8):444-52. PubMed PMID: 18607402

[24]. Brownlee M. The pathobiology of diabetic complications a unifying mechanism. Diabetes. 2005 Jun;54(6):1615-1625. PubMed PMID:15919781.

[25]. Tahrani AA, Askwith T, Stevens MJ. Emerging drugs for diabetic neuropathy. Expert Opin Emerg Drugs. 2010 Dec;15(4):661-683. PubMedPMID:20795891.
[26]. Guerrero-Romero F, Rodríguez-Morán M. Relationship of microalbuminuria with the diabetic foot ulcers in type II diabetes. J Diabetes Complications. 1998 Jul-Aug;12(4):193-196. PubMed PMID:9647336.

[27]. Venkatachalam MA, Griffin KA, Lan R, Geng H, Saikumar P, Bidani AK. Acute kidney injury: a springboard for progression in chronic kidney disease. Am J Physiol Renal Physiol. 2010 May;298(5):F1078-1094. PubMed PMID:20200097.

[28]. McDonald HI, Thomas SL, Millett ER, Nitsch D. CKD and the risk of acute, community-acquired infections among older people with diabetes mellitus: a retrospective cohort study using electronic health records. Am J Kidney Dis. 2015 Jul;66(1):60-68. PubMed PMID:25641062.

[29]. Chawla LS, Kimmel PL. Acute kidney injury and chronic kidney disease: an integrated clinical syndrome. Kidney Int. 2012 Sep;82(5):516-24. PubMed PMID:22673882.

[30]. Viswanathan V, Thomas N, Tandon N, Asirvatham A, Rajasekar S, Ramachandran A, et al. Profile of diabetic foot complications and its associated complications-a multicentric study from India. J Assoc Physicians India. 2005 Nov;53:933-936. PubMed PMID:16515230. 